\title{
The use of modelling studies to inform planning of health services: case study of rapidly increasing endoscopy services in Australia
}

Hannah E. Carter ${ }^{1 *}$ (D), Dylan Knowles ${ }^{2}$, Timothy Moroney ${ }^{3}$, Gerald Holtmann $^{4,9}$, Tony Rahman ${ }^{5}$, Mark Appleyard ${ }^{6}$, Nick Steele ${ }^{7}$, Michael Zanco ${ }^{8}$ and Nicholas Graves ${ }^{1}$

\begin{abstract}
Background: Demand for gastrointestinal endoscopy in Australia is increasing as a result of the expanding national bowel cancer screening program and a growing, ageing population. More services are required to meet demand and ensure patients are seen within clinically recommended timeframes.

Methods: A discrete event simulation model was developed to project endoscopy waiting list outcomes for two large metropolitan health services encompassing 8 public hospitals in Australia. The model applied routinely collected health service data to forecast the impacts of future endoscopic demand over 5 years and to identify the level of service activity required to address patient waiting times and meet key policy targets. The approach incorporated evidence from the literature to produce estimates of cost-effectiveness by showing longer term costs and Quality Adjusted Life Years (QALYs) associated with service expansion.

Results: The modelling revealed that doing nothing would lead to the number of patients waiting longer than clinically recommended doubling across each health service within 5 years. A 38\% overall increase in the number of monthly procedures available was required to meet and maintain a target of $95-98 \%$ of patients being seen within clinically recommended timeframes to the year 2021. This was projected to cost the funder approximately $\$ 140$ million in additional activity over a 5 year period. Due to improved patient outcomes associated with timely intervention, it was estimated that the increased activity would generate over 22,000 additional QALYs across the two health services. This translated to an incremental cost-effectiveness ratio of $\$ 6467$ and $\$ 5974$ per QALY for each health service respectively.
\end{abstract}

Conclusions: Discrete event simulation modelling provided a rational, data based approach that allowed decision makers to quantify the future demand for endoscopy services and identify cost-effective strategies to meet community needs.

Keywords: Endoscopy, Discrete event simulation, Service planning, Cost-effectiveness, Waiting list, Model

\footnotetext{
* Correspondence: Hannah.carter@qut.edu.au

${ }^{1}$ Australian Centre for Health Services Innovation, Queensland University of

Technology, 60 Musk Ave, Kelvin Grove, QLD 4059, Australia

Full list of author information is available at the end of the article
}

(c) The Author(s). 2019 Open Access This article is distributed under the terms of the Creative Commons Attribution 4.0 International License (http://creativecommons.org/licenses/by/4.0/), which permits unrestricted use, distribution, and reproduction in any medium, provided you give appropriate credit to the original author(s) and the source, provide a link to the Creative Commons license, and indicate if changes were made. The Creative Commons Public Domain Dedication waiver (http://creativecommons.org/publicdomain/zero/1.0/) applies to the data made available in this article, unless otherwise stated. 


\section{Background}

The use of data in health care is undergoing a revolution. Health services are increasingly utilizing information technology, including electronic health records, to capture accurate and comprehensive information across all levels of patient interactions with the system [1]. Health related apps and wearable technology provide a repository of data, with implications for research still evolving. Also emerging is the potential for Blockchain technology to create immense, decentralized, patient generated health databases that are updated in real time [2]. Although challenges exist, the use of routinely collected administrative health data has the potential to transform health service planning. Specifically, the wealth of available data can provide decision makers with a rich and constantly evolving understanding of the broader system which in turn enhances their ability to plan for and deliver effective and efficient services.

Discrete event simulation (DES) is a modelling technique that is able to capitalize on the value inherent in detailed patient-level data. DES models are typically designed to represent the process flow of a complex system and the way in which individuals move through and interact with other agents in the system [3]. This provides a systematic, transparent and comprehensive approach to applying data and evidence in the decision making process. Over the past decade, DES models have emerged as an increasingly important and powerful tool in health service management and delivery [4]. The use of individual simulations, as well as the incorporation of time to event parameters, mean that DES techniques are uniquely placed to model the effects of capacity constraints and waiting lists [5].

In Australia, waiting lists for public endoscopy services have rapidly increased over the past decade driven by population growth and ageing, the introduction of a National Bowel Cancer Screening Program (NBCSP) [6], the increasing need for ongoing surveillance procedures and the substitution of surgical techniques with endoscopy procedures [7]. This trend is expected to continue over the next several years in line with population trends and the expansion of the NBCSP to cover bi-annual screening for all Australians aged 50 to 74 years by 2020 . As a result, many health services are becoming unable to see all patients within the clinically recommended time frames. Addressing this issue was identified as an area of priority by the state health department responsible for funding and delivering public endoscopy procedures in a metropolitan region of South-East Queensland, Australia.

The aim of this study was to develop a DES model to inform endoscopy service planning in two large public health services. The model was designed to forecast the impacts of future endoscopic demand and to identify activity levels required to reduce waiting list times and meet policy targets. In addition, it incorporated estimates of future costs and Quality Adjusted Life Years (QALYs), allowing incremental cost-effectiveness ratios to be produced.

\section{Methods}

A discrete event simulation (DES) model of the endoscopy system was developed using AnyLogic [8] to capture the major patient pathways from referral through to diagnosis and ongoing follow up care. A screenshot of the model structure in AnyLogic is in Additional file 1. The model adopted a timeframe of 5 years and was separately applied to two large, public metropolitan health services referred to hereafter as health service A (HSA) and health service B (HSB). Both were similar in size and nature, with each containing four hospital-based endoscopy units and servicing a community population of approximately 900,000 and 1 million people respectively.

\section{Model structure}

A visual depiction of the model is in Fig. 1. Category 4 patients were the most urgent and had a 30 day clinically recommended timeframe for being seen by a specialist, while category 5 were recommended to be seen within 90 days and category 6 within 365 days. The type of follow up care patients' received after an endoscopy was informed by clinical guidelines; this was consistent with service provision and confirmed by a recent internal audit of post-endoscopy management in HSB. Post-endoscopy outcomes were assumed to have implications for patient quality of life, health system costs and mortality rates.

\section{Data inputs}

A comprehensive list of data inputs are in Additional file 2. Data on patient presentations, waiting list outcomes, endoscopy outcomes and costs within the endoscopy system were largely populated with existing administrative data. Where existing data were not available, estimates were based on an audit of hospital data. Estimates of the 5 year survival rates, costs and utility weights associated with postendoscopy ongoing care states were sourced from the literature.

The Australian health care system is funded by both state and federal budgets, with hospital procedures, including endoscopy services, largely funded by state governments. Costs in this study were valued from the perspective of the state government in recognition of their role as the decision maker in this context.

QALY estimates were derived by multiplying the length of time a patient spent in a given health state, multiplied by the utility weight assigned to that health state. Utility weights are a measure of patient presence on a scale where zero is equivalent to death, and one is 


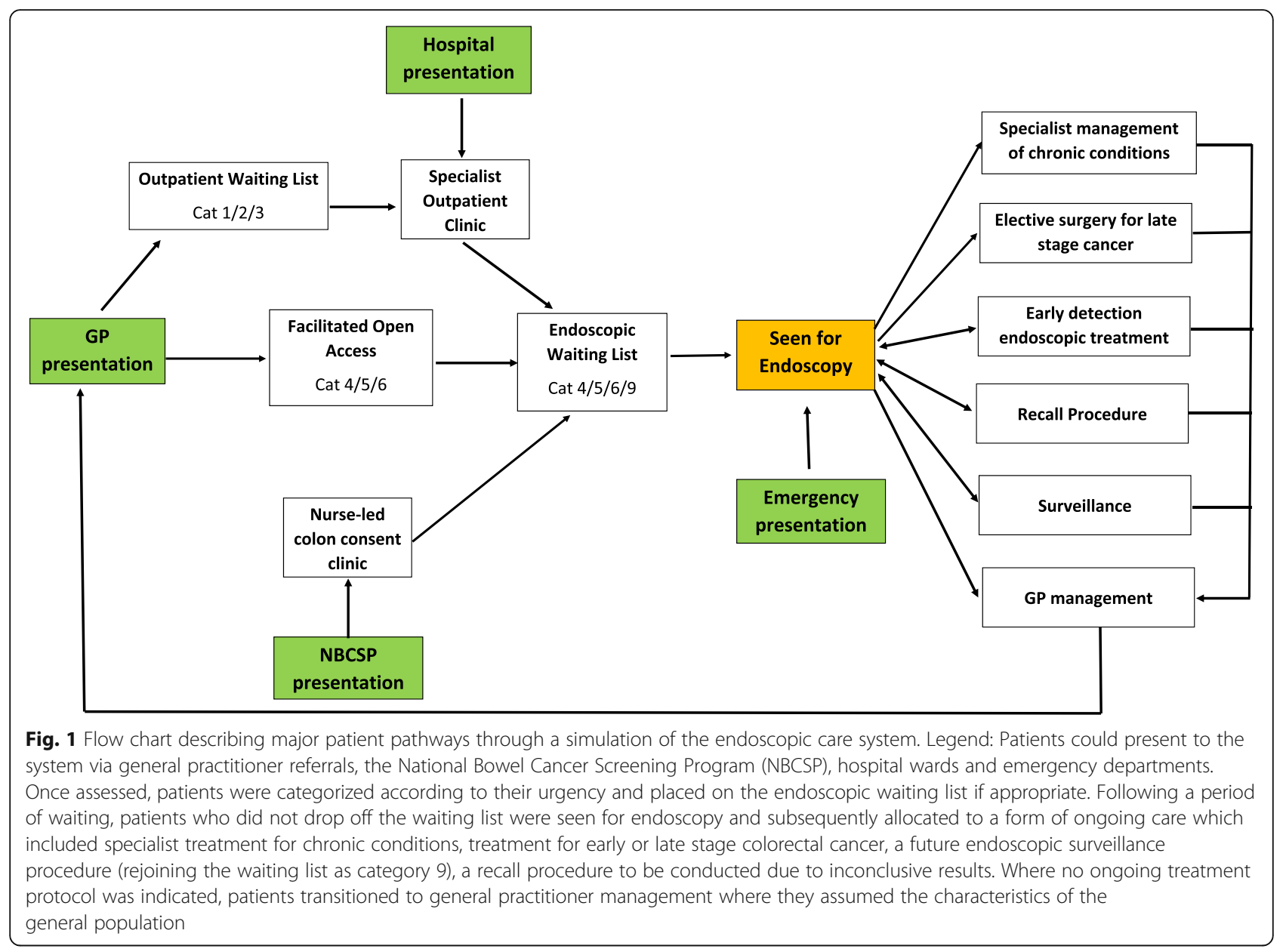

equivalent to full health [9]. As utility values were not directly available from the administrative datasets, these were sourced from the published literature and applied to the chronic condition, early bowel cancer and advanced bowel cancer health states. We adopted the simplifying assumption that all other health states in the model had a utility weight equivalent to one.

\section{Modelled scenarios}

A 'do nothing' scenario was modelled to provide a baseline estimate of waiting list, cost and QALY impacts over 5 years under the assumption that no changes to existing endoscopy services were implemented. The model then ran a number of simulations to estimate the waiting list impacts associated with specific increases in the weekly number of endoscopic procedures available. Category specific targets were set and the model was used to simulate the capacity and funding levels required to reach these within a given timeframe. Targets were set to achieve $98 \%$ of Category 4 patients, and $95 \%$ of category 5 and 6 patients, being seen within clinically recommended waiting times. Patients who breached their clinically recommended waiting time are referred to as 'long waits'.

The modelled results have been reported in terms of increased levels of capacity within the system. It is not assumed that capacity directly correlates with activity levels. Rather, capacity levels reflect the upper limit of possible activity. Activity levels within the model are instead driven by waiting list sizes and demand projections. At various points within the model, activity may be equal to or less than the overall capacity limit. Costs and QALY outcomes are based on the level of activity.

\section{Key assumptions}

The model adopted the annual demand projections provided by the state health department; this included initial presentations via general practitioner, outpatient, NBCSP and emergency settings, as well as subsequent presentations including for surveillance, recall or early detection endoscopic treatment.

Waiting list numbers and waiting times were also modelled to reflect known data, including data on monthly waiting list trends where available. Surveillance patients were classified as category 9 with clinically recommended 
waiting times that varied between 1 to 5 years as prescribed by national clinical guidelines [10]. Given there was no pre-defined administrative process for prioritising patients on the waiting list, the model ran a number of experiments to determine how to best align the modelled process to known trends. The best fit resulted from a process whereby emergency department patients had immediate priority (reflecting real world practice), followed by categories 4, 5, 6 and 9 patients, prioritized by how close they were to breaching their clinically recommended waiting times. For example, a category 4 patient at $66 \%$ of their goal time (i.e. 20 days waiting) was prioritized above a category 6 patient at $50 \%$ of their goal time (i.e. 182 days waiting). This was further augmented by a "twenty days" rule whereby patients approaching 20 days before their goal time were more heavily prioritised. While this rule was not an explicit guideline used in waiting list management, we found that it was able to provide the best fit in reflecting real world outcomes. Specifically, it affected category four patients more strongly than other patients due to their short goal time (i.e. 30 days), helping to keep their waiting times more consistently managed as observed in practice.

Despite a prioritisation process that emphasised proximity to clinically recommended waiting times, an element of 'randomness' was built into this process in order to more closely reflect reality. As such, patients were not necessarily treated in the order they were added to the waiting list. This prioritisation logic enabled the model to closely mirror observed patient waiting times and long wait trends.

Increased capacity for endoscopy procedures may be attained by either extending the operating hours of existing procedure rooms, building new procedure rooms, or a combination of both. Also required for the expansion of activity levels is a sufficient level of qualified medical and nursing staff, and adequate funding levels to accommodate this. The interplay of these factors varied across each of the individual hospitals and clinics accounted for in the modelling. We therefore determined that accounting for these internal and external constraints on changes to activity levels were beyond the scope of our analysis and more suited to modelling, and decision making, within the individual hospital setting. The analysis presented here therefore does not assume or prescribe to a particular strategy to increase capacity. As a result, costs associated with increasing capacity beyond standard procedure costs (for example, staff overtime or capital costs associated with new equipment or facilities) were excluded from this analysis.

\section{Model validation}

The model was validated through three mechanisms. The first was to closely match well-established waiting list projections and endoscopy costs to the health system under the 'do nothing' scenario. The second was to approximate measures, where possible, from a number of different sources. For example, internal feedback loops were validated against historical trend data. This process included running AnyLogic optimization experiments to reduce the differences in simulated waiting list outcomes versus the non-simulated projections. The third mechanism involved a sense check by experts that included a team of health economists, health service managers and senior clinicians who agreed that the model was performing as they would expect and that results were representative of their system. Further information on the validation process, including calibrated measures and margins of error, are reported in Additional file 3.

\section{Sensitivity analysis}

A sensitivity analysis examined the impact of uncertainty in the demand projections. Scenarios where projections were $20 \%$ lower and $20 \%$ higher than the base case assumption were modelled.

\section{Results}

The base case model predicted an increase in long wait patients by $46 \%$ for HSA and $97 \%$ for HSB (Table 1) between 2017 and 2021, assuming no increases to the number of endoscopy procedures available.

For HSA, the model identified a tipping point at 480 procedures per week. At this capacity level, patient outcomes began to dramatically improve but improvement was inconsistent across categories and did not allow for clinically recommended wait times to be met within modelled targets. To sustain target clinical waiting times over the course of the 5 year projections, the model estimated that an increase in the number of available procedures by $37 \%$ to 560 procedures per week would be necessary. For HSB, a tipping point was found at $480-510$ procedures per week, depending on urgency category. An increase of $38 \%$, to 580 procedures per week was required to meet and sustain waiting list targets.

The cost to the funder of increasing capacity levels to those recommended by the modelling was estimated to be $\$ 82.9$ million over 5 years for HSA, translating to 12 , 819 QALYs gained and an ICER of $\$ 6467$ per QALY (Table 2). For HSB, the estimated cost was $\$ 60.8$ million over 5 years, with 10,177 QALYs gained and an ICER of $\$ 5974$ per QALY.

A sensitivity analysis revealed that a $20 \%$ reduction in projected demand levels would require less than half of the additional capacity and costs estimated under the base case scenario in each health service (Table 3). Conversely, demand levels $20 \%$ higher than projected would translate to a total cost increase of $66 \%$ across HSA and HSB combined. 
Table 1 Projected increases to long wait patients by category under a 'do nothing' scenario

\begin{tabular}{|c|c|c|c|c|c|c|c|}
\hline \multirow[t]{2}{*}{ Category } & \multicolumn{6}{|c|}{ Number of long wait patients } & \multirow[b]{2}{*}{$\%$ change $2017-2021$} \\
\hline & Model starting point & 2017 & 2018 & 2019 & 2020 & 2021 & \\
\hline \multicolumn{8}{|c|}{ Health Service A } \\
\hline 4 & $\#$ & 632 & 533 & 486 & 480 & 507 & $-20 \%$ \\
\hline 5 & \# & 2154 & 2396 & 2603 & 2942 & 3347 & $55 \%$ \\
\hline 6 & $\#$ & 360 & 554 & 601 & 654 & 743 & $106 \%$ \\
\hline Total & $\#$ & 3146 & 3483 & 3690 & 4076 & 4596 & $46 \%$ \\
\hline \multicolumn{8}{|c|}{ Health Service B } \\
\hline 4 & $\#$ & 330 & 242 & 217 & 245 & 273 & $-17 \%$ \\
\hline 5 & $\#$ & 946 & 1080 & 1292 & 1607 & 1937 & $105 \%$ \\
\hline 6 & $\#$ & 0 & 89 & 162 & 241 & 308 & - \\
\hline Total & $\#$ & 1276 & 1410 & 1670 & 2092 & 2517 & $97 \%$ \\
\hline
\end{tabular}

\# Data are not publicly available and have been omitted due to their sensitive nature. Figures are below those reported for subsequent years

\section{Discussion}

This is the first Australian study to apply simulation modelling to inform decision making in endoscopic service planning. The model estimated that a 37 and 38\% increase in the number of weekly procedures available was required for HSA and HSB respectively to meet and sustain waiting list targets over 5 years. This translated to an ICER of $\$ 6667$ per QALY for HSA and \$5974 per QALY for HSB. When considering a recent estimate of a reference ICER for the Australian health care system of $\$ 28,003$, this represents a high value use of resources [11]. This lends support to the evidence that bowel cancer screening is a cost-effective intervention $[12,13]$.

The use of DES techniques to inform service planning in health care is an emerging field. A 2010 study used a combination of simulation modeling and linear programming with the aim of reducing access times for endoscopy services in a teaching hospital in the Netherlands [14]. The authors reported that more efficient scheduling practices were able to overcome long access times and allow for performance targets to be met. Further, a 2017 study used DES methods combined with demand forecasting in a hybrid approach that aimed to improve the match

Table 2 Modelled cost-effectiveness outcomes

\begin{tabular}{|c|c|c|c|c|c|c|}
\hline \multirow{2}{*}{$\begin{array}{l}\text { Cost-effectiveness } \\
\text { outcomes }\end{array}$} & \multicolumn{3}{|c|}{ Health Service A $(N=91,564)$} & \multicolumn{3}{|c|}{ Health Service B $(N=84,805)$} \\
\hline & $\begin{array}{l}\text { Current capacity ( } 410 \\
\text { procedures) }\end{array}$ & $\begin{array}{l}\text { Recommended capacity } \\
\text { (560 procedures) }\end{array}$ & Difference & $\begin{array}{l}\text { Current capacity ( } 420 \\
\text { procedures) }\end{array}$ & $\begin{array}{l}\text { Recommended capacity } \\
\text { (580 procedures) }\end{array}$ & Difference \\
\hline \multicolumn{7}{|c|}{ Costs to funder over 5 years ( $\$$ Millions) } \\
\hline $\begin{array}{l}\text { Nurse-Led Colon } \\
\text { Consent Clinic }\end{array}$ & 0.44 & 0.5 & 0.1 & 0.5 & 0.5 & 0.0 \\
\hline $\begin{array}{l}\text { Specialist } \\
\text { Outpatient Clinic }\end{array}$ & 8.5 & 8.5 & 0.0 & 8.6 & 8.6 & 0.0 \\
\hline $\begin{array}{l}\text { Facilitated Open } \\
\text { Access }\end{array}$ & 3 & 3 & 0.0 & 3 & 3 & 0.0 \\
\hline $\begin{array}{l}\text { Elective surgery } \\
\text { costs }\end{array}$ & 10.5 & 12.7 & 2.2 & 10.5 & 12.4 & 1.9 \\
\hline $\begin{array}{l}\text { Endoscopy costs: } \\
\text { outpatient }\end{array}$ & 145.7 & 191.8 & 46.1 & 154.7 & 195.8 & 41.1 \\
\hline $\begin{array}{l}\text { Endoscopy costs: } \\
\text { inpatient }\end{array}$ & 108.8 & 142.8 & 34 & 65.1 & 82.6 & 17.5 \\
\hline Total costs to funder & 278.2 & 361.1 & 82.9 & 243.1 & 303.9 & 60.8 \\
\hline $\begin{array}{l}\text { Average QALYs per } \\
\text { patient }^{\mathrm{a}}\end{array}$ & 2.03 & 2.17 & 0.14 & 2.00 & 2.12 & 0.12 \\
\hline Total QALYs & 185,875 & 198,694 & 12,819 & 169,610 & 179,787 & 10,177 \\
\hline ICER & $\$ 6467$ per QALY & & & $\$ 5974$ per QALY & & \\
\hline
\end{tabular}


Table 3 Additional capacity levels and costs associated with changes to demand projections

\begin{tabular}{llll}
\hline Modelled outcomes & Base case & Lower estimate & Upper estimate \\
\hline Health Service A & & 920 & 1380 \\
Monthly presentations & 1150 & 70 & 240 \\
Recommended capacity increase & 150 & 31.8 & 136 \\
Health service funder costs over 5 years $(\$ M)^{\mathrm{a}}$ & 82.9 & 960 & 1140 \\
Health Service B & 1200 & 70 & 240 \\
Monthly presentations & 160 & 17 & 104 \\
Recommended capacity increase & 60.8 & \\
Health service funder costs over 5 years $(\$ \mathrm{M})^{\mathrm{a}}$ & & & 17 \\
\hline
\end{tabular}

${ }^{\mathrm{a} C o s t s}$ relate to additional activity only

between demand and capacity [15]. The approach was determined to provide plausible forecasts that could inform future health service capacity planning and resource allocation. DES methods have also been used to evaluate operational performance in a colonoscopy suite, accounting for factors including the number of endoscopists, procedure rooms, and turnaround time [16]. Other recent studies have applied DES modelling to analyse waiting list outcomes in outpatient neurosurgery and orthopedic clinics, as well as for surgical procedures [17-21].

A key strength of our analysis was its ability to model a complex, integrated and multi-facility system. As noted in a 2010 review of DES modelling in health care, such studies are typically unit-specific and model discrete components of broader systems, for example, an emergency department, clinic or operating room. [4] The model presented here comprises a comprehensive, system-level representation that spans multiple referral and assessment points as well a number of post-endoscopy patient health states. An additional strength of the approach we have taken is the use of existing, routinely collected data to populate the model. This has the advantage of saving on both the time and cost associated with prospective data collection, and allows for the model to be constantly updated over time. The identification of clear tipping points in both settings highlighted the potential for this modelling technique to identify the minimum required service level to improve waiting list outcomes in the context of growing demand.

While the flexibility inherent in simulation modelling is one its core strengths, it does require specialized expertise and software that may limit its accessibility to many organisations. The use of individual level data also means that these techniques are often best suited to modelling a specific unit or system, with limitations for generalisability. As such, this analysis should be viewed as a case study that has been tailored to the two health services in question. The results cannot be assumed to apply in other endoscopy services.

There were a number of limitations we encountered with the use of administrative datasets for simulation modelling, a purpose for which it was not originally intended. These data were able to provide good estimates of process based measures, for example waiting list numbers and waiting list movements. However, we identified several gaps in these numbers when extrapolating to overall demand or activity levels. For example, several patients undergo an endoscopy without ever being on the waiting list; this could be following an emergency department presentation or as part of an unplanned hospital admission. These presentations needed to be accounted for separately which involved synthesizing different datasets that were not directly comparable, and augmenting these estimates with clinical opinion. There were other challenges we encountered that may be generalized to administrative health service data more broadly. A major limitation was the lack of patient reported outcome measures, for example quality of life. As a result, our analysis is limited by the simplifying assumption that patients are in a state equivalent to full health for the duration of time they spend waiting to be seen for an endoscopy. Utility values reflecting the health related quality of life for patients with cancer and chronic conditions were taken from the published literature, but it is unknown whether they may differ in this cohort specifically. Long term clinical outcomes including patient survival were also unavailable, further limiting the ability of the model to capture patient health outcomes over the longer term.

Another limitation of the administrative data we used was the use of health service reimbursement rates as a proxy for cost of service provision. There is evidence that the actual costs incurred by the health service may vary across sites [22]. This discrepancy may ultimately inhibit best practice decision making for the sites in question. Our model assumes a constant marginal cost per additional procedure. In practice however, there may be higher marginal costs of additional activity (for example due to staff overtime or capital expenditure on new facilities or equipment), or conversely, lower marginal costs achieved through greater economic efficiencies. Marginal costs depend on the level of latent capacity within the system as 
well as decision makers' preferences for managing additional activity; we did not have sufficient information to incorporate these considerations into the model. In addition, we have only accounted for the costs borne by the immediate decision maker, the state health department. This excludes any nationally funded longer term costs associated with ongoing care including pharmaceutical costs, outpatient visits and medical procedures.

Not captured in our model are issues relating to the supply of qualified medical staff if activity levels were to be increased to recommended levels. Sustaining a health workforce that can meet the demands of an ageing population has been identified as a key policy challenge in Australia [23]. A limited supply of endoscopists may have implications for waiting lists beyond what can be addressed through funding for increased activity levels. Further, there is some evidence to suggest that longer procedure times may be associated with higher rates of adenoma detection [24]. These findings are preliminary and need to be examined in further studies, but highlight the potential clinical implications that need to be considered in increasing activity levels within a service.

Despite these limitations, we understand that the outcomes of this study were useful to policy makers. Senior decision makers within the state health department have confirmed that the modelled findings helped inform funding allocations as part of an action plan to improve access to endoscopy and reduce the number of long wait patients. The plan saw the allocation of $\$ 160$ million over 4 years to increase the number of endoscopy services provided across the state by 50,000 .

\section{Conclusions}

Health service decision makers are increasingly faced with financial pressures that reflect growing, ageing populations as well as more costly clinical interventions. In response to concerns around the sustainability of the health care system, there has been a movement towards value base care whereby decision makers aim to maximise health benefits from fixed budgets. The use of data to inform rational decision making with a focus on cost-effectiveness is critical to achieving this aim. The methods we have presented here may have implications for health service managers in making a case for investments in new infrastructure based on forward looking capacity planning, as opposed to small annual funding increments that may contribute to over-burdened services.

Our results demonstrate the power of discrete event simulation in using patient level data to inform health care decision making, specifically in terms of managing demand and improving waiting list outcomes. The model was able to provide a recommendation of the level of service activity required to meet specific policy targets within given timeframes, as well as an estimate of the cost-effectiveness associated with this. This provided decision makers with a rational, data based approach in determining the allocation of scarce health care resources.

\section{Additional files}

Additional file 1: Model structure. Screenshot of the model structure as developed within the Anylogic software program. (JPG $774 \mathrm{~kb}$ )

Additional file 2: Model inputs. A comprehensive summary of the modelled input parametes and respective data sources. (PDF $118 \mathrm{~kb}$ )

Additional file 3: Validation processes. A detailed description of the model validation process, including calibrated measures and margins of error. (PDF $80 \mathrm{~kb}$ )

\section{Abbreviations}

DES: Discrete event simulation; HSA: Health Service A; HSB: Health Service B; ICER: Incremental cost-effectiveness ratio; NBCSP: National Bowel Cancer Screening Program; QALY: Quality adjusted life year

\section{Acknowledgements}

Not applicable

\section{Authors' contributions}

All authors (HC, DK, TM, GH, TR, MA, NS, MZ, NG) made substantial contributions to the conception or design of the work. HEC, TM and GH acquired the data. HEC and DK analysed the data. All authors had access to and interpreted the data. HEC drafted the manuscript and all authors critically revised it for intellectual content. All authors gave final approval and agree to be accountable for all aspects of the work.

\section{Funding}

The research was funded by Queensland Health. The funders were involved in the data collection process. Authors TM, NS and MZ assisted with the interpretation of data and in revising the manuscript.

\section{Availability of data and materials}

The full set of modelled input data is available from the corresponding author on request. Data was sourced from administrative databases including the Queensland Gastrointestinal Endoscopy Data Collection and the Queensland Admitted Patient Data Collection (https://www.health.qld. gov.au/_data/assets/pdf_file/0034/843199/data_custodian_list.pdf).

Ethics approval and consent to participate

An ethics exemption was granted by the Queensland University of Technology Human Research Ethics Committee (exemption number 1600000904). Administrative approval for the use of data from internal databases that were not publicly accessible was provided by Queensland Health.

Consent for publication

Not applicable; no individual patient data was used in this study.

Competing interests

TM, NS and MZ were employed by the department within Queensland Health that funded the research.

\section{Author details}

${ }^{1}$ Australian Centre for Health Services Innovation, Queensland University of Technology, 60 Musk Ave, Kelvin Grove, QLD 4059, Australia.

${ }^{2}$ Anthrodynamics Simulation Services Australia, Homebush, NSW 2140, Australia. ${ }^{3}$ Healthcare Purchasing and System Performance, Queensland Health, 33 Charlotte St, Brisbane, QLD 4001, Australia. ${ }^{4}$ Faculty of Medicine \& Faculty of Health \& Behavioural Sciences, University of Queensland, 288 Herston Rd, Herston, QLD 4006, Australia. ${ }^{5}$ The Prince Charles Hospital, Rode Road, Chermside, QLD 4032, Australia. 'Royal Brisbane and Women's 
Hospital, Butterfield St, Herston, QLD 4029, Australia. ${ }^{7}$ Healthcare Purchasing and System Performance, Queensland Health, 33 Charlotte St, Brisbane, QLD 4001, Australia. ${ }^{8}$ Health systems innovation branch, Queensland Health, 33 Charlotte St, Brisbane, QLD 4001, Australia. ${ }^{9}$ Department of Gastroenterology \& Hepatology, Princess Alexandra Hospital, 199 Ipswich Rd, Woolloongabba, QLD 4102, Australia.

Received: 7 March 2019 Accepted: 19 August 2019

Published online: 29 August 2019

\section{References}

1. Buntin M, Burke M, Hoaglin M, Blumenthal D. The benefits of health information technology: a review of the recent literature shows predominantly positive results. Health Aff. 2011;30(3):464-71.

2. Mettler M: Blockchain technology in healthcare: The revolution starts here. In: IEEE 18th International Conference on e-Health Networking, Applications and Services (Healthcom). Munich: IEEE; 2016: 1-3. https://doi.org/10.1109/ HealthCom.2016.7749510.

3. Karnon J, Stahl J, Brennan A, Caro JJ, Mar J, Moller J, Force I-SMGRPT. Modeling using discrete event simulation: a report of the ISPORSMDM modeling good research practices task Force--4. Value Health. 2012;15(6):821-7.

4. Günal MM, Pidd M. Discrete event simulation for performance modelling in health care: a review of the literature. J Simul. 2010;4(1):42-51.

5. Karnon J, Haji Ali Afzali H. When to use discrete event simulation (DES) for the economic evaluation of health technologies? A review and critique of the costs and benefits of DES. Pharmacoeconomics. 2014;32(6):547-58.

6. Ananda S, McLaughlin S, Chen F, Hayes I, Hunter A, Skinner I, Steel M, Jones I, Hastie I, Rieger N, et al. Initial impact of Australia's national bowel cancer screening program. Med J Aust. 2009;191(7):378-81.

7. Draganov PV, Wang AY, Othman MO, Fukami N. AGA Institute Clinical Practice Update: Endoscopic Submucosal Dissection in the United States. Clin Gastroenterol Hepatol. 2019;17(1):16-25. e11.

8. Anylogic [https://www.anylogic.com/].

9. Torrance GW. Measurement of health state utilities for economic appraisal: a review. J Health Econ. 1986;5(1):1-30.

10. National Health and Medical Research Council: Clinical Practice Guidelines for Surveillance Colonoscopy. 2011.

11. Edney $L$, Afzali $H$, Cheng $T$, Karnon J. Estimating the reference incremental cost-effectiveness ratio for the Australian health system. PharmacoEconomics. 2018;36(2):239-52.

12. Pignone M, Flitcroft K, Howard K, Trevena L, Salkeld G, St John D. Costs and cost-effectiveness of full implementation of a biennial faecal occult blood test screening program for bowel cancer in Australia. Med J Aust. 2011; 194(4):180-5.

13. Pignone M, Saha S, Hoerger T, Mandelblatt J. Cost-effectiveness analyses of colorectal cancer screening: a systematic review for the US preventive services task Force. Ann Intern Med. 2002:137(2):96-104.

14. Joustra P, De Wit J, Struben V, Overbeek B, Fockens P, Elkhuizen S. Reducing access times for an endoscopy department by an iterative combination of computer simulation and linear programming. Health Care Manag Sci. 2010;13(1):17-26.

15. Harper A, Mustafee N, Feeney M. A hybrid approach using forecasting and discrete-event simulation for endoscopy services. In: 2017 Winter Simulation Conference (WSC): 2017. Las Vegas: IEEE; 2017. p. 1583-94.

16. Berg B, Denton B, Nelson H, Balasubramanian H, Rahman A, Bailey A, Lindor K. A discrete event simulation model to evaluate operational performance of a colonoscopy suite. Med Decis Mak. 2010;30(3):380-7.

17. Comans TA, Chang AT, Standfield L, Knowles D, O'Leary S, Raymer M. The development and practical application of a simulation model to inform musculoskeletal service delivery in an Australian public health service. Operations Res Health Care. 2017;15:13-8.

18. Standfield L, Comans T, Raymer M, O'Leary S, Moretto N, Scuffham P. The efficiency of increasing the capacity of physiotherapy screening clinics or traditional medical services to address unmet demand in Orthopaedic outpatients: a practical application of discrete event simulation with dynamic queuing. Appl Health Econ Health Policy. 2016;14(4):479-91.

19. Comas M, Castells X, Hoffmeister L, Román R, Cots F, Mar J, GutiérrezMoreno S, Espallargues M. Discrete-event simulation applied to analysis of waiting lists. Evaluation of a prioritization system for cataract surgery. Value Health. 2008;11(7):1203-13.
20. Vasilakis C, Sobolev B, Kuramoto L, Levy A. A simulation study of scheduling clinic appointments in surgical care: individual surgeon versus pooled lists. J Oper Res Soc. 2007;58(2):202-11.

21. VanBerkel PT, Blake JT. A comprehensive simulation for wait time reduction and capacity planning applied in general surgery. Health Care Manag Sci. 2007;10(4):373-85.

22. Duckett SJ, Breadon P, Weidmann B, Nicola I. Controlling costly care: a billiondollar hospital opportunity. Grattan Institute: Melbourne; 2014.

23. Armstrong BK, Gillespie JA, Leeder SR, Rubin GL, Russell LM. Challenges in health and health care for Australia. Med J Aust. 2007;187(9):485-9.

24. Barclay RL, Vicari JJ, Doughty AS, Johanson JF, Greenlaw RL. Colonoscopic withdrawal times and adenoma detection during screening colonoscopy. N Engl J Med. 2006;355(24):2533-41.

\section{Publisher's Note}

Springer Nature remains neutral with regard to jurisdictional claims in published maps and institutional affiliations.

\section{Ready to submit your research? Choose BMC and benefit from:}

- fast, convenient online submission

- thorough peer review by experienced researchers in your field

- rapid publication on acceptance

- support for research data, including large and complex data types

- gold Open Access which fosters wider collaboration and increased citations

- maximum visibility for your research: over $100 \mathrm{M}$ website views per year

At $\mathrm{BMC}$, research is always in progress.

Learn more biomedcentral.com/submissions 